\title{
Mechanics Altered
}

National Cancer Institute

\section{Source}

National Cancer Institute. Mechanics Altered. NCI Thesaurus. Code C62960.

Problem associated with a device mechanical functioning of machinery, moving parts or tools of device being changed or modified. 